\title{
Fatal haematemesis arising from benign oesophagoatrial fistula
}

\author{
M R ZEIDERMAN, JANE T O'GRADY \\ From the University Department of Surgery and the Department of Histopathology, Northern General Hospital, \\ Sheffield
}

\begin{abstract}
An 86 year old woman with a Barrett's oesophagus, a benign oesophageal stricture, and a benign ulcer developed an oesophagoatrial fistula. As in previously reported cases, she died after a massive haematemesis.
\end{abstract}

The presence of a fistulous communication between the oesophagus and the cardiac chambers is uncommon, particularly in the absence of previous surgery or malignant disease. Only five cases have been reported; a further case is described below.

\section{Case report}

An 86 year old woman, known to have a Barrett's oesophagus with a benign oesophageal stricture above a hiatus hernia, was admitted to hospital after haematemesis. Dilatation of the stricture had been undertaken on four occasions over the preceding 15 months. Medication included cimetidine, digoxin, frusemide, and amiloride but not oral potassium supplements. On admission she was clinically anaemic and in atrial fibrillation at a rate of 80 beats/min. Her blood pressure was $170 / 65 \mathrm{~mm} / \mathrm{Hg}$ and there was evidence of mild congestive cardiac failure. Abdominal examination showed some epigastric tenderness and rectal examination revealed melaena stool. The results of investigations were: haemoglobin $8.6 \mathrm{~g} / \mathrm{dl}$, white blood cells $13.8 \times$ $10^{9} / 1$, platelets $400 \times 10^{9} / 1$, urea $9 \cdot 3 \mathrm{mmol} / 1$. At endoscopy the presence of a Barrett's oesophagus was confirmed and the squamocolumnar junction was noted to be $23 \mathrm{~cm}$ from the incisor teeth. Four $\mathrm{cm}$ below the squamocolumnar junction was a macroscopically benign oesophageal ulcer with fresh clot at its centre. The ulcer was not bleeding. The gastroscope passed easily through the site of previous stricture formation and the remainder of the examination showed nothing abnormal.

After transfusion her condition remained stable for 24 hours. She than had a further massive haematemesis followed by cardiac arrest. Resuscitation was unsuccessful.

At necropsy the findings were those of an ulcer arising on the anterior wall of a Barrett's oesophagus (fig 1) and penetrating the full thickness of the muscle wall to enter the left atrium (fig 2). The fistulous communication was about

Address for reprint requests: Mr M R Zeiderman, University Surgical Unit, Clinical Sciences Centre, Northern General Hospital, Sheffield S5 7AY.

Accepted 29 April 1988
$1.5 \mathrm{~cm}$ in diameter. The stomach and the remainder of the gastrointestinal tract contained both fresh and altered blood. There was no evidence of ulceration elsewhere. Histological examination confirmed the presence of a benign peptic ulcer arising in an oesophagus lined by columnar epithelium of gastric type.

\section{Discussion}

Direct penetration of benign oesophageal ulcers into the pericardium,' aorta, ${ }^{2}$ and coronary arteries $^{3}$ has been reported but fistulous communication with the cardiac chambers is uncommon. There have been several reports of

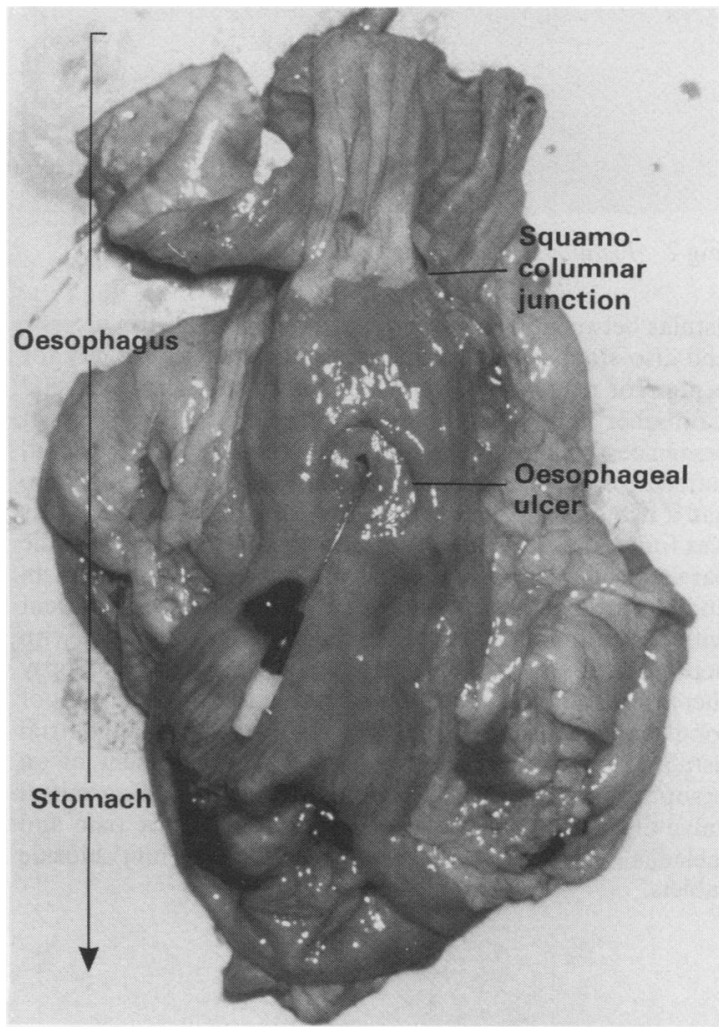

Fig 1 Benign oesophageal ulcer with probe through the site of the oesophagoatrial fistula. The ulcer clearly lies below the squamocolumnar junction. 


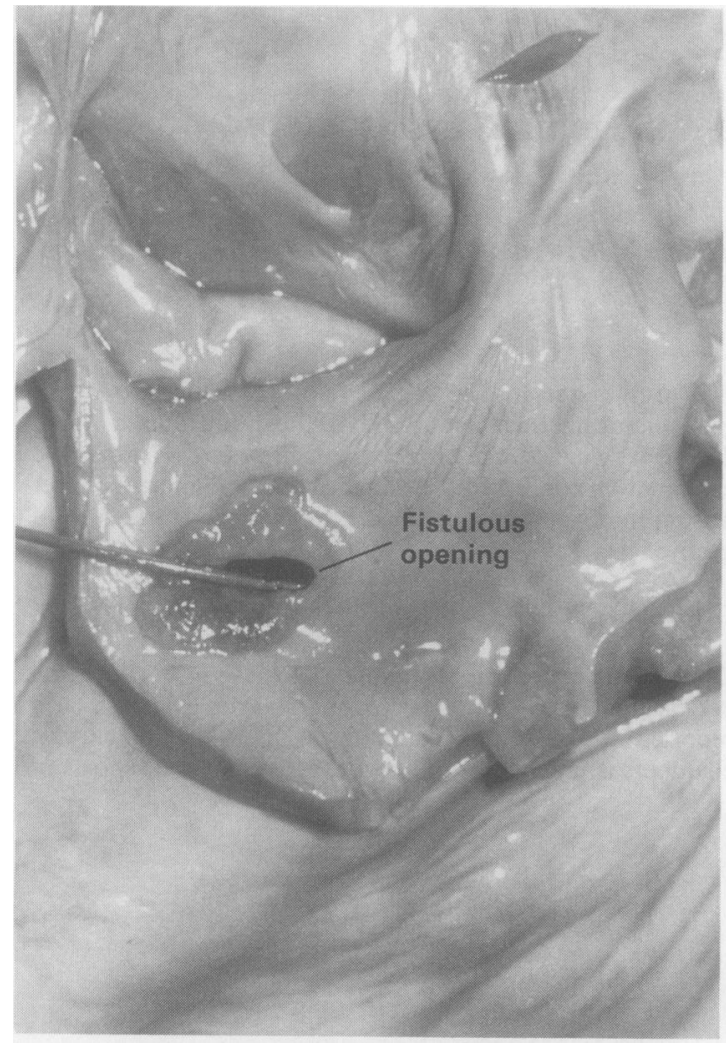

Fig 2 Fistulous opening within the left atrium.

fistulas between the left ventricle and benign gastric ulcers ${ }^{45}$ and also stomal ulcers that have occurred after surgery for benign $^{6}$ or malignant disease. ${ }^{7}$ Not until 1970 , however, did Laubscher ${ }^{8}$ report what appears to be the first true case of benign oesophagoatrial fistula. A 20 year old soldier who had suffered "trauma to the oesophagus" in childhood and who had a two year history of epigastric pain relieved by antacids was found dead in bed. Death was due to penetration of the bare area of the heart by a benign oesophageal ulcer. Itabashi and Granada ${ }^{9}$ and Mott and Austin ${ }^{10}$ each reported a patient with longstanding reflux oesophagitis who presented with neurological abnormalities and haematemesis. At necropsy there were multiple areas of cerebral infarction as a result of food embolisation in association with an oesophagoatrial fistula. Sumithran et $a l^{11}$ reported the development of an oesophagoatrial fistula in a man with longstanding mitral valve disease and a two year history of epigastric pain and melaena, who was receiving slow release potassium chloride tablets.
The presence of an oesophagoatrial fistula in a 77 year of man with a four week history of epigastric pain was describeg by Cunnane. ${ }^{12} \mathrm{~A}$ benign oesophageal ulcer was seen endoscopy and a barium swallow showed no evidence of fistula. His epigastric pain continued despite medical trea ment and three months after admission he died sudden from a massive gastrointestinal haemorrhage.

In common with the five cases described above our patient had suffered with longstanding oesophagitis. Mott and Austin ${ }^{10}$ have suggested that a chronic inflammatory reactio $\overrightarrow{b_{0}}$ is necessary to allow the ulcer tract sufficient time to penetrae through the wall of the oesophagus and atrium, wit obliteration of the pericardium. Also in common with the other patients, our patient had a relatively mild initiáp haematemesis, which occurred 36 hours before massive haemorrage and death. The initial haemorrhage may be smadb because the pressures within the left atrium and oesophagus are similar. Further bleeding will occur as left heart failure develops and left atrial pressure rises. All patients with oesophagoatrial fistula have died. Penetration of oes\& phageal ulcers into surrounding structures is not uncommo? Unfortunately such patients are frequently of advanced ags and the diagnosis is considered in only a few, with uniform poor results.

We wish to thank Mr K Rogers for allowing us to report the case.

\section{References}

1 Stephenson SE Jr, Maness G, Scott HW Jr. Oesophagopericardi fistula of benign origin. J Thorac Surg 1958;36:208-13.

2 Sloop RD, Thompson JC. Aorto-esophageal fistula: report of case and review of literature. Gastroenterology 1967;53:768-72

3 Matthews HR. Haematemesis from a coronary artery caused by penetration of a gastric ulcer in a hiatus hernia. Br Heart 9 . 1974;36:1141-3.

4 Oser P. Ein Fall von Perforation eines runden Magengeschwures in das linken Herz. Wien Med Blatter 1880;52.

5 Kennedy A. Peptic ulceration affecting the left ventricle. Thorax 1983;38:630-1.

6 Prolla JC, Taebel DW, Kirsner JB. Perforation of oesophagogastric anastomotic ulcer into the left atriun? Gastroenterology 1967;52:871-4.

7 Brynjolfsson G, Kania R, Bekeris L. Gastroesophageal cardiac fistula due to perforation of an esophagogastric anastomoti ulcer into the left atrium. Hum Pathol 1980;2:677-9. 8 Laubscher FA. Esophagocardiac fistula. Report of a case. N Ength

9 Itabashi HH, Granada LO. Cereberal food embolism secondary t: esophageal-cardiac perforation. JAMA 1972;219:373-5.

10 Mott LJM, Austin GE. Cerebral embolization resulting fro esophageal-atrial fistula. Arch Intern Med 1976;136:718-20. N

11 Sumithran E, Lim KH, Chiam HL. Atrio-oesophageal fistu complicating mitral valve disease. Br Med J 1979;ii:1552-3.

12 Cunnane K. Esophagoatrial fistula. Can J Surg 1978;21:466-7. 